\title{
Infant feeding and adult glucose tolerance, lipid profile, blood pressure, and obesity
}

\author{
A C J Ravelli, J H P van der Meulen, C Osmond, D J P Barker, O P Bleker
}

\begin{abstract}
Background-It is generally accepted that breast feeding has a beneficial effect on the health of infants and young children. Recently, a few studies have shown that the method of infant feeding is also associated with cardiovascular disease and its risk factors in adult life.

Aims-To examine the association between the method of infant feeding in the first weeks after birth and glucose tolerance, plasma lipid profile, blood pressure, and body mass in adults aged 48-53 years. Methods-Subjects born at term between 1 November 1943 and 28 February 1947 in the Wilhelmina Gasthuis in Amsterdam around the time of a severe period of famine (late November 1944 to early May 1945). For 625 subjects, information was available about infant feeding at the time of discharge from hospital (on average 10.4 days after birth), and at least one blood sample after an overnight fast.

Results-Subjects who were bottle fed had a higher mean 120 minute plasma glucose concentration after a standard oral glucose tolerance test than those who were exclusively breast fed. They also had a higher plasma low density lipoprotein (LDL) cholesterol concentration, a lower high density lipoprotein (HDL) cholesterol concentration, and a higher LDL/ HDL ratio. Systolic blood pressure and body mass index were not affected by the method of infant feeding.

Conclusions-Exclusive breast feeding seems to have a protective effect against some risk factors for cardiovascular disease in later life.

(Arch Dis Child 2000;82:248-252)
\end{abstract}

Keywords: breast feeding; non-insulin dependent diabetes mellitus; cholesterol; blood pressure; obesity

Obstetrics and

Gynaecology,

Academic Medical

Centre

O P Bleker

MRC Environmental Epidemiology Unit, Southampton General Hospital, Southampton SO16 6YD, UK $\mathrm{J} H \mathrm{P}$ van der Meulen C Osmond

D J P Barker

Correspondence to: Dr van der Meulen email: jan.vandermeulen $@$ LSHTM.ac.uk

Accepted 22 October 1999 an extremely high prevalence of non-insulin dependent diabetes mellitus (NIDDM), showed that exclusive breast feeding in the first

Firstly, a recent study in Pima Indians between 10 and 39 years old, a population with two months of life was associated with a lower rate of NIDDM. ${ }^{4}$ The odds of having NIDDM to not having it were $59 \%$ lower in those who were exclusively breast fed compared to those who were exclusively bottle fed. Secondly, it was also found that men born between 1920 and 1930 in Hertfordshire, a rural area north of London, had higher low density lipoprotein (LDL) cholesterol concentrations if they had been exclusively bottle fed, or breast fed beyond the first year of life, whereas the cholesterol concentrations were unrelated to the method of infant feeding in women. ${ }^{5}{ }^{6}$ Studies in children found the highest cholesterol concentrations in the group who had been breast fed for more than six months. ${ }^{7}$ Other studies showed associations between breast feeding and lower cholesterol concentrations, more clearly however in women than in men. ${ }^{8-10}$ Thirdly, blood pressure was shown to be significantly raised in children aged 6 to 10 if they were exclusively breast fed for more than 15 weeks. ${ }^{11}$ Another study indicated that blood pressure was higher in children and adolescents if they were breast fed for more than three months. ${ }^{12}$ Other studies however did not find associations between infant feeding and blood pressure. ${ }^{12-16}$ Lastly, it was also shown that a shorter duration of breast feeding was associated with obesity in children and adolescents, ${ }^{17-19}$ and that the introduction of solids before 15 weeks was associated with heavier and fatter children in the age range 6-10 years. ${ }^{11}$

Recently, we studied the relation between maternal nutrition during gestation and biological risk factors for cardiovascular disease in a cohort of subjects aged about 50 years, who were born between 1943 and 1947 in a university hospital in Amsterdam around the time of the Dutch famine, a period of severe malnutrition in the last five months of the second world war. We found that exposure to famine during late and mid gestation was linked to impaired glucose tolerance, and exposure in early gestation to a more atherogenic lipid profile and, in women, to an increased level of obesity. ${ }^{20-22} \mathrm{~A}$ link between prenatal exposure to famine and blood pressure could not be shown. ${ }^{23}$

In the same cohort, we also studied the relation between the method of infant feeding during the stay in hospital, which lasted on average 10 days, and these risk factors for cardiovascular disease. We compared glucose tolerance, plasma lipid concentrations, blood pressure, and level of obesity in subjects who had been exclusively breast fed during the first 10 days of their life with those who were at least partly bottle fed. 
Subjects and methods

The design and data collection procedure of the Dutch Famine Birth Cohort Study has been described in detail elsewhere. ${ }^{20}$ We retrieved the medical records of all 1380 singletons born alive after 37 weeks of gestation between 1 November 1944 and 28 February 1946 in the Wilhelmina Gasthuis in Amsterdam. We also retrieved the medical records of random samples of 650 of the 1305 babies born in the year before this period and of 650 of 2391 babies born in the following year. Of these babies, $27(1.0 \%)$ were excluded because their medical record could not be found, and $239(8.9 \%)$ were excluded because the gestational age at birth was below 259 days. Therefore, 2414 subjects were eligible to be included. We invited 912 subjects who still lived in or close to Amsterdam to visit the Academic Medical Centre after an overnight fast. Of these, $32(3.5 \%)$ were excluded because they had been diagnosed with diabetes mellitus in the past. A total of 741 subjects attended the clinic between March 1995 and August 1996.

We took the method of infant feeding at the day of hospital discharge from the medical records, and classified it as exclusive breast feeding, partial bottle feeding, or exclusive bottle feeding. The method of infant feeding was missing in 67 subjects. We also considered the method of feeding to be missing if the hospital stay was less than seven days (10 subjects) or more than 31 days (16 subjects). Of the 648 participants with information about infant feeding, 625 had a fasting blood sample taken. Birth weights among these 625 participants differed neither from the remainder of the 2414 subjects who were originally eligible, nor from the remainder of the 912 subjects who were invited to attend the clinic.

Maternal characteristics and birth data were also abstracted from the medical records. Socioeconomic status at birth was determined from the occupation of the head of the family, which was dichotomised into manual and nonmanual class. Current socioeconomic status was determined from the subject's or their partner's occupation, whichever was highest, according to a scale that represents the education needed for it and the income generated by it, ranging from 16 for the lowest to 87 for the highest status. ${ }^{24}$

We performed an oral glucose tolerance test, taking blood samples at 0,30 , and 120 minutes after a $75 \mathrm{~g}$ oral glucose load. The fasting insulin and 32-33 split proinsulin concentrations were considered as a measure of insulin resistance, because they reflect the degree of exposure of the pancreatic beta cell to glucose and so to increased demands for insulin. ${ }^{25}$ The 30 minute relative insulin increment $\log ((30$ min insulin - fasting insulin)/30 min glucose) was calculated as a measure of insulin deficiency. ${ }^{26}$ We also took fasting blood samples to measure lipid and lipoprotein concentrations. Blood pressure was the average of four measurements in the non-dominant arm, taken twice before and twice after the other examinations with an automated auscultatory device
(Profilomat), while the subjects were seated for at least five minutes. We measured waist circumference midway between the costal margin and iliac crest and hip circumference at the widest part of the hips, generally at the level of the greater trochanter. Body mass index was calculated as weight $(\mathrm{kg})$ divided by the square of height $\left(\mathrm{m}^{2}\right)$.

Subjects were considered to be exposed to famine in utero if the official daily rations set weekly by the authorities were less than 1000 calories $(0.00418 \mathrm{MJ})$ during any 13 week period of gestation. According to this definition, babies born between 7 January 1945 and 28 April 1945 were exposed in late gestation, babies born between 29 April 1945 and 18 August 1945 were exposed in mid gestation, and babies born between 19 August 1945 and 8 December 1945 were exposed in early gestation. The official rations for children younger than one year were always higher than 1000 calories, which indicates that they were relatively protected against undernutrition. ${ }^{27}$ Pregnant and lactating women received food supplements of about 4000 calories (0.01672 MJ) per week, but during the early months of 1945 these supplements were not always available.

We compared the differences between subjects who were exclusively breast fed and those who were at least partly bottle fed with multiple linear regression for continuously distributed variables and logistic regression for the dichotomous indicator of impaired glucose tolerance (120 minutes plasma glucose concentration $\geqslant 7.8 \mathrm{mmol} / \mathrm{l})$. We log transformed some continuous variables before analysis because of their skewed distributions. We tabulated these variables as geometric means and standard deviations, and presented the relative differences between feeding methods. We always adjusted for sex, prenatal exposure to famine in late, mid, or early gestation, maternal age, and length of hospital stay when testing differences. In a second step, we also adjusted for other maternal characteristics, birth outcomes, and adult characteristics.

\section{Results}

Of the 625 subjects included in this study, 520 $(83.2 \%)$ had been exclusively breast fed during their stay in hospital, $99(15.8 \%)$ were partly bottle fed, and six $(1.0 \%)$ were exclusively bottle fed. The proportion of subjects who had been exclusively breast fed varied slightly according to prenatal exposure to famine: 82 of $101(81.2 \%)$ in those exposed to famine during late gestation; 80 of $91(87.9 \%)$ in those exposed during mid gestation; and 54 of 63 $(85.7 \%)$ in those exposed during early gestation (table 1). People who had been exclusively breast fed were more often men, had younger mothers who suffered less often from mastitis, and they were discharged from hospital about two days earlier. All other characteristics did not differ appreciably according to the method of feeding.

When adjusting for sex, prenatal exposure to famine, maternal age, and length of hospital stay, we found that subjects who were bottle fed 
Table 1 Characteristics at birth by infant feeding

\begin{tabular}{lllll}
\hline & $\begin{array}{l}\text { Exclusively } \\
\text { breast fed }\end{array}$ & Bottle fed & Total (SD) & $\begin{array}{l}\text { Missing } \\
\text { observations }\end{array}$ \\
\hline Number of participants (n) & 520 & 105 & 625 & 0 \\
Male & $48.8 \%$ & $45.7 \%$ & $48.3 \%$ & 0 \\
Exposure to famine & & & & \\
In late gestation (n) & 82 & 19 & 101 & \\
In mid gestation (n) & 80 & 11 & 91 & \\
In early gestation (n) & 54 & 9 & 63 & \\
Not exposed during gestation & 304 & 66 & 370 & \\
Maternal characteristics & & & & 0 \\
Age (years) & 28.7 & 31.2 & $29.1(6.5)$ & 0 \\
Primiparous & $32.9 \%$ & $35.2 \%$ & $33.3 \%$ & 0 \\
Low level of education & $87.4 \%$ & $81.5 \%$ & $86.4 \%$ & 116 \\
Manual class & $63.5 \%$ & $62.8 \%$ & $63.4 \%$ & 103 \\
Weight gain 3rd trimester (kg) & 3.5 & 3.6 & $3.5(3.2)$ & 176 \\
Weight last prenatal visit (kg) & 66.2 & 65.3 & $66.1(8.5)$ & 71 \\
Mastitis & $2.7 \%$ & $5.7 \%$ & $3.2 \%$ & 0 \\
Birth characteristics & & & & \\
Gestational age (days) & 285 & 285 & $285(12)$ & 81 \\
Birth weight (g) & 3366 & 3326 & $3359(460)$ & 0 \\
Length of hospital stay after birth (days) & 10.2 & 11.8 & $10.4(3.4)$ & 0 \\
Stay in incubator & $1.9 \%$ & $4.8 \%$ & $2.4 \%$ & 0 \\
Adult characteristics & & & & \\
Socioeconomic status & 47.5 & 48.2 & $47.6(13.6)$ & 0 \\
Low level of education $\dagger$ & $64.2 \%$ & $68.6 \%$ & $65.0 \%$ & 0 \\
\hline Primary school complet & & & & \\
\hline
\end{tabular}

^Primary school completed or lower.

†Lower general secondary education completed or lower.

had higher 120 minute plasma glucose concentrations and a higher prevalence of impaired glucose tolerance than those who were exclusively breast fed (table 2). They also had higher fasting insulin and 32-33 split proinsulin concentrations, which suggests some degree of insulin resistance. The 30 minute relative insulin increment, a measure of insulin deficiency, did not differ according to the method of infant feeding. Fasting LDL cholesterol and apolipoprotein $\mathrm{B}$ concentrations were higher in those who were bottle fed, as well as the LDL/HDL (high density lipoprotein) cholesterol ratios, which indicates a more atherogenic lipid profile. Systolic and diastolic blood pressures did not differ according to the method of infant feeding, neither did the level of obesity in terms of body mass index and waist circumference, and the body fat distribution in terms of waist to hip ratio.

None of these results changed appreciably when we adjusted additionally for other maternal characteristics (parity, level of education, socioeconomic status), birth characteristics (birth weight, stay in incubator), and adult characteristics (socioeconomic status, level of education). For example, after adjustment for all these variables, 120 minute glucose concentration was $10.1 \%$ (95\% confidence interval 2.7 to 18.1 ) higher, fasting insulin concentration was $15.8 \%$ (3.3 to 30.0 ) higher, fasting 32-33 split proinsulin concentration was $27.6 \%$ (8.5 to 50.1 ) higher, LDL cholesterol concentration was $0.22 \mathrm{mmol} / 1$ (0.00 to 0.43 ) higher, HDL cholesterol concentration was $5.6 \%$ (0.3 to 10.7$)$ lower, LDL/HDL ratio was $11.4 \%$ (2.2 to 21.5 ) higher, and triglyceride concentration was $8.3 \%$ ( -3.6 to 21.8$)$ higher among those bottle fed than among those exclusively breast fed.

The differences according to the method of infant feeding with respect to the insulinglucose metabolism seemed to be similar in men and women. For example, the 120 minute glucose concentration was $8.6 \%$ ( -2.1 to 20.3$)$ higher in at least partly bottle fed men, and $12.3 \%$ (2.3 to 23.3 ) higher in at least partly bottle fed women, compared with those who were exclusively breast fed. The differences with respect to the lipid concentrations however seemed to be, albeit not significantly, larger among women than among men. We found among women that LDL cholesterol was $0.30 \mathrm{mmol} / 1$ (0.00 to 0.60$)$ higher, HDL

Table 2 Geometric means (SD) of adult outcomes by infant feeding

\begin{tabular}{|c|c|c|c|c|c|}
\hline & $\begin{array}{l}\text { Exclusively breast fed } \\
(n=520)\end{array}$ & $\begin{array}{l}\text { Bottle fed } \\
(n=105)\end{array}$ & $\begin{array}{l}\text { Total (SD) } \\
(n=625)\end{array}$ & $p$ Value ${ }^{\star}$ & $\begin{array}{l}\text { Missing } \\
\text { observations }\end{array}$ \\
\hline \multicolumn{6}{|l|}{$\begin{array}{l}\text { Oral glucose tolerance test } \\
\text { Fasting }\end{array}$} \\
\hline Glucose $(\mathrm{mmol} / \mathrm{l}) \dagger$ & 5.69 & 5.87 & $5.72(1.2)$ & 0.01 & 0 \\
\hline Insulin $(\mathrm{pmol} / \mathrm{l}) \dagger$ & 46.4 & 52.7 & $47.4(1.7)$ & 0.01 & 8 \\
\hline Proinsulin $(\mathrm{pmol} / \mathrm{l}) \dagger$ & 5.84 & 6.67 & $5.97(1.9)$ & 0.01 & 9 \\
\hline Fasting $32-33$ split proinsulin $(\mathrm{pmol} / \mathrm{l}) \dagger$ & 6.24 & 7.65 & $6.45(2.1)$ & 0.003 & 12 \\
\hline \multicolumn{6}{|l|}{30 minutes } \\
\hline Glucose $(\mathrm{mmol} / \mathrm{l}) \dagger$ & 8.80 & 9.10 & $8.85(1.3)$ & 0.07 & 17 \\
\hline Insulin $(\mathrm{pmol} / \mathrm{l}) \dagger$ & 307.4 & 312.2 & $308.2(1.8)$ & 0.6 & 25 \\
\hline Insulin increment & 3.36 & 3.35 & $3.36(0.7)$ & 0.9 & 32 \\
\hline \multicolumn{6}{|l|}{120 minutes } \\
\hline Glucose $(\mathrm{mmol} / \mathrm{l}) \dagger$ & 5.87 & 6.47 & $5.97(1.4)$ & 0.005 & 9 \\
\hline Glucose $\geqslant 7.8 \mathrm{mmol} / 1$ & $13.8 \%$ & $24.3 \%$ & $15.6 \%$ & 0.006 & 9 \\
\hline Insulin $(\mathrm{pmol} / \mathrm{l}) \dagger$ & 5.18 & 5.30 & $5.20(0.9)$ & 0.3 & 17 \\
\hline \multicolumn{6}{|l|}{ Lipids } \\
\hline Total cholesterol (mmol/l) & 5.95 & 6.11 & $5.97(1.0)$ & 0.1 & 3 \\
\hline LDL cholesterol $(\mathrm{mmol} / \mathrm{l})$ & 3.96 & 4.15 & $3.99(1.0)$ & 0.06 & 3 \\
\hline HDL cholesterol $(\mathrm{mmol} / \mathrm{l}) \dagger$ & 1.34 & 1.27 & $1.33(1.3)$ & 0.03 & 3 \\
\hline LDL/HDL ratio $\dagger$ & 2.86 & 3.14 & $2.90(1.5)$ & 0.01 & 3 \\
\hline Triglyceride $(\mathrm{g} / \mathrm{l}) \dagger$ & 1.13 & 1.19 & $1.14(1.7)$ & 0.1 & 3 \\
\hline Apolipoprotein A1 (g/l) & 1.54 & 1.52 & $1.54(0.3)$ & 0.4 & 6 \\
\hline Apolipoprotein B (g/l) & 1.21 & 1.27 & $1.22(0.3)$ & 0.07 & 6 \\
\hline \multicolumn{6}{|l|}{ Blood pressure } \\
\hline Diastolic (mm Hg) & 85.7 & 84.8 & $85.6(10.1)$ & 0.4 & 0 \\
\hline Systolic (mm Hg) & 125.1 & 124.9 & $125.1(15.4)$ & 0.9 & 0 \\
\hline \multicolumn{6}{|l|}{ Anthropometry } \\
\hline Body mass index $\left(\mathrm{kg} / \mathrm{m}^{2}\right) \dagger$ & 26.8 & 27.2 & $26.9(1.2)$ & 0.3 & 0 \\
\hline Waist circumference $(\mathrm{cm})$ & 91.9 & 93.2 & $92.1(12.8)$ & 0.1 & 2 \\
\hline Waist to hip ratio $(\times 100)$ & 87.3 & 87.7 & $87.4(8.8)$ & 0.1 & 2 \\
\hline
\end{tabular}

${ }^{*} \mathrm{p}$ Value adjusted for prenatal exposure to famine, maternal age, sex, and hospital duration.

tGeometric mean. 
cholesterol was $7.9 \%$ (0.8 to 14.5$)$ lower, LDL/HDL ratio was $16.0 \%$ (2.7 to 30.9$)$ higher, and triglycerides were $10.4 \%$ ( -4.9 to 28.0) higher in those bottle fed than in those exclusively breast fed. Corresponding differences in men were $0.11 \mathrm{mmol} / 1(-0.21$ to 0.42$)$ for LDL cholesterol, $-3.8 \%$ (-11.2 to 4.3 ) for HDL cholesterol, $6.9 \%$ (-5.2 to 20.5) for $\mathrm{LDL} / \mathrm{HDL}$ ratio, and $7.3 \%-9.9$ to 27.9 ) for triglycerides.

\section{Discussion}

We found that 50 year old subjects who had been at least partly bottle fed during the first weeks of life had a lower glucose tolerance, possibly owing to some degree of insulin resistance, and a more atherogenic lipid profile than those who had been exclusively breast fed. The deleterious effects of bottle feeding on the lipid profile seemed to be slightly stronger in women than in men. The method of infant feeding did not affect adult blood pressure or body mass.

This study is based on information about the method infant of feeding as it was noted in the medical records at discharge. We only distinguished between those who were exclusively breast fed and the remainder, because exclusive bottle feeding was very rare. The characteristics of these two groups were remarkably similar. Adjusting for these characteristics did not affect the associations between method of feeding and glucose tolerance or lipid profile. It is therefore unlikely that our findings can be merely attributed to differences in biological or behavioural determinants of the method of feeding. It is also important to note in this respect, that if the associations between infant feeding and adult health outcomes were confounded by, for example, socioeconomic status at birth or at adult age, or the level of education, one would have expected to find associations between infant feeding and blood pressure or body mass, neither of which were found. ${ }^{28}$

About $40 \%$ of the subjects included in this study were exposed to famine in utero. A number of arguments indicate that it is unlikely that this exposure to undernutrition of the women and their babies has affected the associations found between bottle feeding and the reduced glucose tolerance and atherogenic lipid profile at adult age. Firstly, our figures indicate that $81.2 \%$ of the mothers who were undernourished during late pregnancy (those who gave birth during the famine period) were able to exclusively breast feed their babies compared to $83.6 \%$ of the others. In those days, additional bottle feeding was given, if weighing the newborn baby immediately before and after breast feeding indicated an insufficient milk supply. ${ }^{29}$ Secondly, lactating women were entitled to additional weekly supplies. ${ }^{27}$ Moreover, a large number of studies have shown that women are able to produce milk with adequate content of protein, fat, carbohydrate, and most minerals even when their own nutrition is limited. ${ }^{30}$ Thirdly, children under 3 years were regarded as a group that must be protected and the official rations for this group never fell below 1000 calories, which was adequate according to the then prevailing standards. $^{27}$

We do not have information about the method of infant feeding after discharge from hospital, which took place on average 10 days after birth, but we still found relatively large deleterious effects on glucose tolerance and cholesterol concentrations in adult life. In those days, women were advised to breast feed their babies exclusively for seven to nine months. ${ }^{29}$ It is therefore likely that those who were exclusively breast feeding their babies at discharge tried to maintain breast feeding for at least several months. This view is corroborated by figures kept by the Municipal Health Authority of Amsterdam in the years immediately before the second world war which show that about $55 \%$ of the babies were still exclusively breast fed at the age of 3 months. ${ }^{31}$ Moreover, Dutch paediatricians had the impression that the duration of breast feeding was not greatly affected during the famine. ${ }^{32}$ Bottle feeds most commonly consisted of diluted cows' milk (milk and water in the proportion of $1: 1$ or $2: 1$ ) with some added sugar, or buttermilk with rice flour and sugar, which gave it a similar energy content, but a higher protein and lower fat content than human milk. ${ }^{29}$

Which factors could explain the effects of breast feeding on insulin-glucose and lipid metabolism? One explanation is that the considerable increases in fat content which are present during breast feeding but not during bottle feeding might provide a satiety signal, which protects against overfeeding. ${ }^{33} 34$ Furthermore, it has been shown that bottle fed babies have a different hormonal response of which the higher insulin response is of particular interest. ${ }^{35}$ Since the early 1970s, a large number of experiments with the baboon as animal model were performed to investigate through which mechanism lipid metabolism is affected by breast feeding or infant feeding (see McGill et $a l^{\beta 6}$ for review). In contrast to our findings, these studies showed that breast fed baboons had a more atherogenic profile, especially lower HDL cholesterol concentrations, throughout their life than bottle fed ones. More detailed studies eliminated nutritional factors such as cholesterol content, type of fat, or under- or overfeeding as mechanisms by which infant nutrition affects lipid metabolism in adult life. This suggests that biologically active substances like growth factors or hormones that are contained in breast milk are responsible for the effect on lipid metabolism. ${ }^{37}$ For instance, lipid metabolism might be permanently affected by changes in thyroid homoeostasis induced by the observed higher circulating triiodothyronine concentrations in the bottle fed animals. It has also been shown recently that leptin is produced in the mammary gland and absorbed by the child, thereby potentially influencing growth and development. $^{38} 39$

Whatever the underlying factors may be, our findings correspond largely with those of previous studies on associations of infant feeding 
with specific risk factors for cardiovascular disease. The associations of bottle feeding with insulin resistance and an atherogenic lipid profile, but not with hypertension or obesity suggest that nutrition during early life is not the "common soil" that contributes to the "insulin resistance syndrome", the occurrence of these risk factors for cardiovascular disease in the same person, ${ }^{40}$ which is in agreement with our observations in the same group of subjects with respect to different effects of prenatal exposure to famine on glucose tolerance, lipid profile, obesity, and blood pressure. ${ }^{20-23}$

Our results support the hypothesis that the method of infant feeding is an important determinant of health in adult life. Babies who were exclusively breast fed during the first days of their life had favourable outcomes with respect to glucose and lipid metabolism, which relates to a lower risk of cardiovascular disease. However, our understanding of the mechanisms linking infant nutrition and cardiovascular disease is poor. ${ }^{36}$ Because of the potential importance for the prevention of cardiovascular disease, it is important that the research in the area of infant nutrition should also focus on biological effects in later life. ${ }^{41}$

We thank all men and women of the Dutch Famine Birth Cohort who participated in the study. We thank Marjan Loep, Mieneke Vaas, Lydia Stokwijk, Yvonne Graafsma, Jokelies Knopper, and Maartje De Ley and the Special Research Unit of the Academic Medical Centre, University of Amsterdam for collecting the data. We thank the Gemeentearchief of Amsterdam for retrieving the birth records and the Bevolkingsregister dam for retrieving the birth records and the Bevolkingsregister of Amsterdam for tracing the subjects. The study was funded by land, WellBeing, UK, and the British Diabetic Association, Academic Medical Centre, Amsterdam, Netherlands.

1 Cambell C. Breast feeding and health in the Western World. Br 7 Gen Pract 1996;46:613-17.

2 Golding J, Emmett PM, Rogers IS. Does breast feeding have any impact on non-infectious, non-allergic disorders? Early Hum Dev 1997;49:S131-42.

3 Morley R, Lucas A. Nutrition and cognitive development. Mr Med Bull 1997;53:123-34.

4 Pettitt DJ, Forman MR, Hanson RL, Knowler WC, Bennet $\mathrm{PH}$. Breastfeeding and the incidence of non-insulindependent diabetes mellitus in Pima Indians. Lancet 1997 350:166-8.

5 Fall CHD, Barker DJP, Osmond C, Winter PD, Clark PMS, Hales CN. Relation of infant feeding to adult serum cholesterol concentration and death from ischaemic heart disease. Br f Obstet Gynaecol 1992;304:801-5.

6 Fall C, Osmond C, Barker DJP, Clark MPS, Hales CN, Stirling Y, Meade TW. Fetal growth and cardiovascular disease in women. BMf 1995;310:428-32.

7 Hromadova J, Kostalova L, Leskova L, Kapellerova A. Relationship between the duration of the breast-feeding period and the lipoprotein profile of children at the age of 13 years. Physiol Res 1997;46:21-5.

8 Marmot MG, Page CM. Effect of breast-feeding on plasma cholesterol and weight in young adults. $\mathcal{F}$ Epidemiol Community Health 1980;34:164-7.

9 Kolacek S, Kapetanovic T, Zimolo A, Luzar V. Early determinants of cardiovascular risk factors in adults. A. Plasma lipids. Acta Paediatr 1993;82:699-704.

10 Kark JD, Troya G, Friedlander Y, Slater PE, Stein Y. Validity of maternal reporting of breast feeding history and the association with blood lipids in 17 year olds in Jerusalem. $\mathcal{F}$ Epidemiol Community Health 1984;38:218-25.

11 Wilson AC, Forsyth JC, Greene SA, Irvine L, Hau C, Howie PW. Relation of infant diet to childhood health: seven years of follow up of cohort of children in Dundee infant feeding study. $B M \mathcal{F}$ 1998;316:21-5.

12 Taittonen L, Nuutinen M, Turtinen J, Uhari M. Perinata and postnatal factors in predicting later blood pressure among children: cardiovascular risk in young Finns. Pediatr Res 1996;40:627-32.
13 Whincup PH, Cook DG, Shaper AG. Early influences on blood pressure: a study of children aged 5-7 years. BMF 1989;299:587-91.

14 Baranowski T, Bryan GT, Harrison JA, Rassin DK, Greaves $\mathrm{KA}$, Baranowski JH. Height, infant-feeding practices and cardiovascular functioning among 3 or 4 year old children in three ethnic groups. F Clin Epidemiol 1992;45:513-18

15 Kolacek S, Kapetanovic T, Luzar V. Early determinants of cardiovascular risk factors in adults B. Blood pressure. Acta Paediatr 1993;82:377-82.

16 Lucas A, Morley R. Does early nutrition in infants born before term programme later blood pressure? $B M F$ 1994;309:304-8.

17 Kramer MS. Do breast-feeding and delayed introduction of solid foods protect against subsequent obesity? f Pediatr 1981;7:883-7.

18 Elliott KG, Kjohede CL, Gournis E, Rasmussen KM. Duration of breastfeeding associated with obesity during adolescence. Obes Res 1997;5:538-41.

19 Von Kries R, Koletzko B, Sauerwald T, Von Mutius E, Barnert D, Grunert V, Von Voss $\mathrm{H}$. Breast feeding and obesity: cross sectional study. BMF 1999;319:147-50.

20 Ravelli ACJ, van der Meulen JHP, Michels RPJ, Osmond C, Barker DJP, Bleker OP. Glucose tolerance in adults after in utero exposure to the Dutch Famine. Lancet 1998;351: 173-7.

21 Roseboom TJ, van der Meulen JHP, Osmond C, Barker DJP, Ravelli ACJ, Bleker OP. Lipid profile in adults after prenatal exposure to famine. Am $\mathcal{F}$ Clin Nutr. [In press.]

22 Ravelli ACJ, van der Meulen JHP, Osmond C, Barker DJP, Bleker OP. Obesity at the age of 50 in men and women
exposed to famine prenatally. Am f Clin Nutr 1999;70:81116 .

23 Roseboom TJ, Van der Meulen JHP, Ravelli ACJ, Van Montfrans GA, Osmond C, Barker DJP, Bleker OP. Blood pressure in adults after prenatal exposure to famine. $\mathcal{F}$ Hypertens 1999;17:325-30.

24 Bakker B, Sieben I. Maten voor prestige, sociaaleconomische status en sociale klasse voor de standaard beroepenclassificatie 1992. Sociale Wetenschappen 1997;40: $1-22$.

25 Hales CN. The pathogenesis of NIDDM. Diabetologia 994;37(suppl 2):S162-8.

26 Wareham NJ, Phillips DIW, Byrne CD, Hales CN. The 30 minute insulin incremental response in an oral glucose tolerance test as a measure of insulin secretion [letter]. Diabet Med 1995;12:931.

27 Burger GCE, Sandstead HR, Drummond JC. Malnutrition and starvation in western Netherlands, September 1944 to fuly 1945. The Hague: General State Printing Office, 1948.

28 Blane D, Hart CL, Davey Smith G, Gillis CR, Hole DJ, Hawthorne VM. Association of cardiovascular disease risk factors with socioeconomic position during childhood and during adulthood. BMF 1996;313:1434-8.

29 Gorter E. Voeding van den zuigeling. Rotterdam: Nijgh \& Van Ditmar, 1934.

30 Institute of Medicine. Nutrition during lactation. Washington: National Academic Press, 1991

31 Medisch Statistisch Bureau van den Gemeentelijken Geneeskundigen Dienst te Amsterdam. Zuigelingenstatistiek: no. 46,1938 and no. $49,1940$.

32 Driessen OA. A half century of infant nutrition. Maandschrift voor de Kindergeneeskunde 1965;33:341-51.

33 Lucas A, Lucas PJ, Baum JD. Pattern of milk flow in breastfed infants. Lancet 1979;ii:57-8.

34 Hamosh M. Does infant nutrition affect adiposity and cholesterol levels in the adult? $\mathcal{F}$ Pediatr Gastroenterol Nutr 1988; 7:10-16.

35 Lucas A, Adrian TE, Blackburn AN, Sarson DL, AynsleyGreen A, Bloom SR. Breast vs bottle: endocrine responses are different with formula feeding. Lancet 1980;i:1267-9.

36 McGill HC, Mott GE, Lewis DS, McMahan CA, Jackson EM. Early determinants of adult metabolic regulation: effects of infant nutrition on adult lipid and lipoprotein metabolism. Nutr Rev 1996;54:S31-40.

37 Leite E, Cowden EA, Friesen HG. Endocrinology of lactation and nursing: disorders of lactation. In: DeGroot LJ, ed. Endocrinology. Philadelphia: WB Saunders, 1995:222438 .

38 Casbiell X, Piñeiro V, Tomé MA, Peinó R, Diéguez C, Casanueva FF. Presence of leptin in colostrum and/or breast milk from lactating mothers: a potential role in the regulation of neonatal food intake. F Clin Endocrinol Metab
1997;82:4270-3.

39 Smith-Kirwin SM, O'Connor DM, Johnston J, De Lancey $\mathrm{E}$, Hassink SG, Funanage VL. Leptin expression in human mammary epithelial cells and breast milk. $\mathcal{f}$ Clin Endocrinol Metab 1998;83:1810-13.

40 Stern MP. Do non-insulin-dependent diabetes mellitus, and cardiovascular disease share common antecedents? Ann Intern Med 1996;124:110-16.

41 Lucas A. Programming by early nutrition: an experimental approach. F Nutr 1998;128:401S-6S. 